\title{
La paradoja del falsificador
}

\author{
F for fake | Orson Welles | 1973 \\ Daniela Koldobsky" \\ Universidad Nacional de Arte (UNA)
}

Recibido: 2 de marzo 2016; aprobado: 15 de marzo 2016

\begin{abstract}
Resumen
A pesar de la atractiva y confusa denominación de "falso documental” para una modalidad cinematográfica con la que F for Fake de Orson Welles (1974) inauguró una época, no está en el centro de este trabajo su imparable recurrencia a conceptos tan distintivos como diversos entre sí -tales como falso, falsificación, fraude, magia, e incluso verdad y mentira (ambas agregadas en el título de la versión del documental en francés y en español)-. Tampoco está el documental como discurso, ni otras importantes nociones. Lo que sí ocupa el centro de este artículo es uno de los temas tratados en ese último trabajo de Welles: la falsificación y la figura del falsificador. Este último será analizado en relación con la célebre figura con la que confronta - la de artista, con un doble objeto. En primer lugar, se trata de examinar el trabajo en las artes visuales, en tanto el arte moderno y contemporáneo en sus diversas disciplinas y lenguajes no han hecho más que evidenciar la diversidad y extensión de modos de producción y operatorias que muchas veces cuestionan toda especificidad del trabajo artístico. Y en segundo lugar, se pretende demostrar cómo, además de patentizar el lugar que en nuestra sociedad tiene la figura del artista, el falsificador esconde una paradoja fundamental: cuestiona el estatuto de artista creador pero su existencia depende de que ese estatuto se mantenga vivo.
\end{abstract}

Palabras clave: artes visuales | falsificación | tekhné | artista

The charm of the forger

\begin{abstract}
Despite the confusing yet attractive name of "false documentary" to describe the cinematographic modality with which Orson Welles's F for Fake (1974) inaugurated an era, his unstoppable recurrence to such distinctive and diverse concepts such as false, falsification, fraud, magic and even truth and lies (both added to the title of the French and Spanish version of the documentary) are not central to this work. Neither is the documentary as discourse, or other important notions. What is at the center of this article is one of the topics Welles addresses in his last work: falsification and the falsifier. The latter will be analyzed in relation to the famous person with whom he confronts - the artist, with a double object. In the first place, the purpose is to examine the work in Visual Arts, as modern and contemporary art in its diverse disciplines and languages have done none other than make evident the diversity and extension of operational and productive modes that very often question every specificity of the artistic work. And in second place, the aim is to demonstrate how, apart from showing the high standing of the figure of artist, the falsifier hides a fundamental paradox: it questions the statute of the artist as creator but its existence depends on keeping that statute alive.
\end{abstract}

Keywords: Visual Arts | falsification | tekhné | artist

\section{La falsificación y la noción de artista}

A diferencia de lo que ocurre con la literatura y la música por ejemplo, la falsificación en pintura es posible en principio debido a su sistema de producción manual que da como resultado un objeto único. Según Nelson Goodman esa especificidad del objeto pictórico permite definirlo como autográfico (1968), y según Gerard Genette se trata de un carácter autográfico con objeto de inmanencia única (1997). Este último concluye que "en ciertas artes el concepto de autenticidad tiene sentido y se define por la historia de producción de una obra y en otras no lo tiene y todas las copias correctas constituyen otros tan- tos ejemplares válidos de la obra" (Genette 1996:22,23). ${ }^{1}$ Si bien el concepto de autenticidad en pintura está ligado a la producción de un objeto único, aspecto que hace que en esos términos en literatura esté descartada, existen en ella por lo menos dos modalidades del denominado fraude literario: la falsa atribución autoral, que se asemeja a la falsa atribución de la falsificación pictórica porque se trata de un autor que firma bajo el nombre de otro autor existente sin contar con su aprobación, y el plagio, que cuenta con muchos ejemplos resonantes en la actualidad literaria argentina y cuyas propiedades son diferentes a las de la falsificación pictórica en primer lugar porque la atribución es opuesta: si en pintura el autor verdadero firma con el

* dkoldobsky@hotmail.com 
nombre de otro, en el plagio literario el autor firma con su nombre pero apropiándose de partes de la obra de otro o de la obra completa. ${ }^{2}$ Lo que define la existencia de la falsificación en la pintura y la hace inútil en otros lenguajes artísticos es entonces el proceso de producción de una obra y su resultado como objeto único, pero como práctica social sólo es útil y pertinente bajo dos condiciones fundamentales: una específica definición de artista individual, y la conformación de un mercado del arte. El objeto de estas páginas es analizar la relación entre la falsificación y la definición de artista -la primera de las condiciones-, pero por la estrecha relación entre ambas, es importante introducir alguna definición respecto a la segunda.

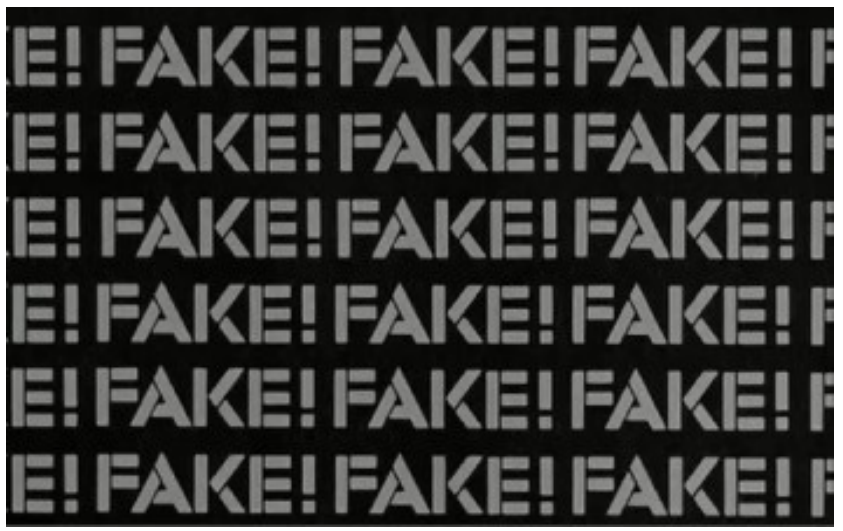

La dimensión económica del arte tiene una presencia no lateralizada en $F$ for fake. El falsificador que protagoniza el documental, Elmyr d'Hory, se excusa diciendo que "si no hubiesen mercados las falsificaciones no existirían". ${ }^{3}$ Efectivamente, el mercado del arte se define en algunos países europeos ya en el siglo XVII sustituyendo al sistema de patronazgo y mecenazgo y determinando nuevas modalidades en la circulación de obras y en la definición de artista. Entre otros aspectos, aparece uno central respecto del concepto de falsificación: la atribución, un trabajo de expertos cuya función es peritar las obras con el objeto de distinguir entre original y copia -o entre la obra auténtica y la que no lo es- y atribuir su autoría ${ }^{4} \mathrm{Si}$ bien los criterios de valoración económica de las obras -especialmente los precios- no se constituyen de modo unívoco ni homogéneo, la firma como indicadora de la autoría de la obra- es uno de los más importantes, pero es fundamental asegurar su veracidad, así como la de los rasgos de un estilo individual. De modo que la falsificación no solamente existe por la presencia de un mercado del arte, sino que a su vez lo desafía. Por otra parte -y también en una relación de doble víael precio alcanzado por la obra influye en el prestigio social del artista y -en el otro sentido- el prestigio adquirido permite elevar su precio. El falsificador es por definición un artista fantasma, ya que su autoría no debe reconocerse públicamente. ${ }^{5}$ Por lo tanto el prestigio le está vedado; sólo le queda la posibilidad de introducir la obra en el mercado y conseguir éxito económico. Si el falsificador es compensado económicamente, ello es a causa de un trabajo realizado, y es a partir de ese trabajo que se puede introducir la relación entre la figura del falsificador y la figura del artista. En otro parlamento de $F$ for fake el mismo d'Hory postula: "Mi profesión es verdadera: pinto falsificaciones". Sus palabras aluden a que por más falsificada que sea la firma de una obra, lo que no es falso es su "fabricación", su proceso productivo manual, el trabajo que debió desplegar su "hacedor". ${ }^{6}$ Tanto el pintor como el falsificador trabajan con una materialidad que es la de la pintura sobre el lienzo, aspecto central en la definición de tekbné que la Antigüedad clásica daba a lo que nuestra cultura define como arte. La tekhné ${ }^{7}$ puede ser definida como un saber hacer, y si bien no agota la descripción de la actividad artística en la actualidad, pone en el centro un tema que los procesos de desmaterialización de las artes visuales y las décadas de arte efímero y conceptual parecen negar: el trabajo planteado incluso como trabajo físico, en la relación con una materia que ofrece resistencia y que implica la invención y el manejo de técnicas específicas como condiciones de la producción artística. Desde el punto de vista de la materialidad y del concepto de tekhné, la pintura falsificada no puede diferenciarse de una que no lo es, porque al haber sido producida a mano ha requerido de un saber hacer volcado en un trabajo cuyo resultado sigue siendo una obra única, es decir, cuenta con una unicidad que según formuló Walter Benjamín en su célebre "La obra de arte en la era de su reproductibilidad técnica”, la carga de un valor cultual. Ese valor, que en el objeto original está dado en parte porque él es testimonio del paso del tiempo, debe ser reeditado en una falsificación, por procedimientos constructivos específicos como la búsqueda de una tela correspondiente a la época del artista falsificado o la adjunción de polvo y suciedad que permitan hacer pasar una pintura realizada recientemente por otra que tiene rastros de su historia temporal. Por lo tanto, dos precisiones respecto de la falsificación, la materialidad y el hacer artístico. En primer lugar, desde el punto de vista material y del proceso de producción, una pintura falsificada no se diferencia de una que no lo es; en ambas está presente un trabajo manual que indica el dominio de unatekhné. En segundo lugar, la pintura falsificada sigue 
gozando de la unicidad que según el citado trabajo de Benjamin es una de las causantes del funcionamiento del aura. Si desde el punto de vista de su producción material una obra "auténtica" y una "falsificada" son iguales, lo que las diferencia y explica la existencia de la falsificación es el concepto de artista creador y el privilegio dado a su figura en los últimos siglos. De allí se desprende la necesidad de desplazar el problema de la falsificación desde la obra hacia la figura de artista.

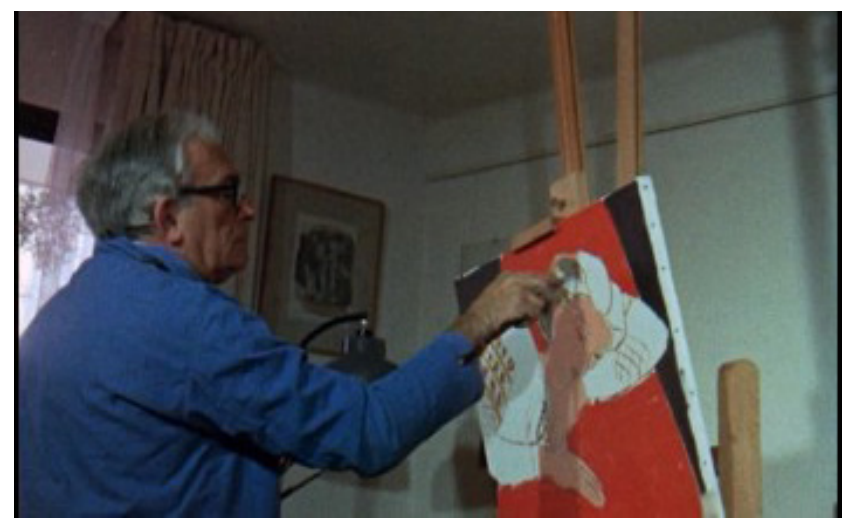

Si bien en la actualidad y como se observará, el trabajo manual no está en el centro de una definición de artista que -sin ser la única- se puede considerar como canónica, sí forma parte fundamental del trabajo del falsificador. Antonio Viñuela -conocido como el falsificador actual más importante de pintura clásica española- lo suscribe, en una defensa de su actividad: "El falsificador para mí es un genio. Su único problema es que suele ser una persona poco conocida. Tápies, Miró y todos esos pintores contemporáneos no valen mucho. Son cartelistas. Lo que ocurre es que tienen detrás a la prensa... Un falsificador es otra cosa, es un artista de verdad, que no alcanza el debido reconocimiento". (Diario El Mundo, abril de 1994). El peyorativo adjetivo de cartelistas(productores de carteles) dado por Viñuela a algunos famosos pintores españoles del siglo XX funciona como una declaración de principios: es artista aquél cuya pintura ostenta una factura cuidada e inclusive virtuosa en términos técnicos, y cuya obra da cuenta de un trabajo minucioso. Es cartelista quien no utiliza boceto previo ni dibujo, cuya obra presenta una pincelada expuesta y que incluso en ocasiones dispensa el gesto corporal del pincel sobre la tela o la conformación de una mancha por sobre una forma definida y "terminada". Viñuela descalifica así a quienes considera no poseedores de ciertas habilidades y destrezas técnicas que entiende son fundamentales para el hacer pictórico. Si el falsificador posee los talentos que permiten que su obra pueda atribuirse a la mano de un artista reconocido en el panteón de la historia, y además necesariamente no trabaja menos que el creador de la obra original, se comprende el fastidio de Viñuela, pero ese fastidio no logra explicar la "utilidad" de su actividad y su inclinación por realizarla. Para acercarse a esa explicación, se debe comparar en principio la figura de artista que describen las palabras de d'Hory y Viñuela, pues ella se encuentra en confrontación con la de su propia época. Si bien Viñuela define a los falsificadores como genios, la definición de artista -y específicamente de pintor- que parece estar presente en sus palabras y en las de d'Hory no es la del artista genio, e incluso no llega a ser todavía la que permitió comenzar a utilizar la noción de artista. La defensa del trabajo manual y de las habilidades técnicas alude por el contrario a la definición de pintor vigente antes del Renacimiento: la de artesano, que despliega una actividad considerada un oficio y cuyo aprendizaje se adquiere en talleres. Ese artesano no firmaba las obras, cuya autoría no era considerada individual, sino producto del trabajo de un taller bajo la dirección de un maestro, a quien la obra se encargaba. A partir del Renacimiento los pintores logran una elevación de su estatus social concomitante con la elevación del estatuto de su práctica, que deja de ser considerada parte de las denominadas artes mecánicas para pasar a ser una de las artes liberales. Sin embargo todavía no se utiliza la noción de artista, más bien el pintor comienza a ser considerado un profesional, es decir, no ya solamente un trabajador manual sino también intelectual, hasta el punto de que Leonardo Da Vinci define a la pintura como "cosa mentale". ${ }^{8}$ De todos modos, todavía esa figura no es la del artista creador, de la que nuestra época es tributaria y por la que la falsificación sufre una condena no sólo económica sino moral. Entre los cambios que se produjeron para que se comenzara a utilizar la noción de artista y que ella aludiera a un creador original está la devaluación del trabajo manual, que dejó de ser considerado definitorio de las capacidades artísticas.

\section{Dos modalidades de falsificación y la definición de artista creador}

Para que una falsificación funcione es fundamental no solamente la presencia del trabajo técnico manual del que d'Hory y Viñuela se sienten orgullosos, sino la imitación de un estilo individual, de un modo de hacer que los falsificadores muestran que no es intransferible. Existen por lo menos dos modalidades de falsificación en 
pintura: la copia de una obra, tan exacta respecto de la ya existente que impide o dificulta que se pueda reconocer como tal, y que se podría definir por lo tanto como una réplica de la pintura original; y la de un estilo o una obra en términos genéricos, de la que el ejemplo más famoso es el holandés Van Meegeren, que en pleno siglo XX pintó varias obras que fueron vendidas como atribuidas a Vermeer (siglo XVII) e introducidas en el mercado de entreguerras como desconocidas y no catalogadas hasta el momento. La imitación de un estilo y de un género -de una serie de operatorias que involucran por un lado una pincelada específica, un trabajo de la forma y del resto de los elementos del lenguaje plástico "a la manera de”, y por otro las leyes de un género pictórico, también "a la manera de"- con el resultado de una obra nueva, es decir, nunca producida por el artista al que se le atribuye, implica una diferencia fundamental respecto de la primera modalidad, ya que produce obras que antes no existían. Por ello Genette aclara: "No se debe confundir la falsificación así definida (copia fraudulenta de una obra singular) con la falsificación por imitación, o pastiche, que consiste en producir (fraudulentamente o no) una obra "original" o al menos nueva, al modo de otro artista: lo que hacía Van Meegeren al modo de Vermeer". (1997: 22) Respecto de la segunda modalidad de falsificación representada por el caso Van Meegeren, la crónica de lo sucedido pocos años luego del fin de la segunda guerra mundial permite explicar dos aristas sugestivas acerca de la falsificación, la figura del falsificador y su funcionamiento en la vida social. Van Meegeren es acusado de colaboracionista por haber vendido un supuesto Vermeer (La cena de Emańs) a un nazi durante la guerra. Como la pena de la traición es la muerte, confiesa que él falsificó esa obra y pinta otra frente a sus acusadores para probar que es realmente un imitador del estilo de Vermeer y no un colaboracionista nazi. En el proceso comenta irónicamente que lo que más le ha costado copiar fue la firma del artista. Por un lado, esto se puede relacionar con el hecho de que la única copia absoluta es la firma, ya que en el resto de la obra no hay un trabajo de duplicación sino de imitación de un estilo. Por el otro, muestra que lo que sella la existencia de una falsificación y define la unicidad de la obra es esa firma. Y además no deja de ser interesante la comparación de delitos y la confluencia de peripecias: Van Meegeren necesita (al modo de la confirmación paradojal presente en $F$ for fake) mostrar la falsedad de la autoría de la obra para dar cuenta de su verdad jurídica y moral y asegurar su subsistencia.
Las dos posibilidades de falsificación descritas -que merecen un tratamiento más extenso que el de estas proposiciones- implican un trabajo que involucra talentos múltiples, pero carecen del rasgo considerado fundamental para la definición de artista que sustituyó a la de profesional liberal: la creación. La definición de la actividad artística como creadora se debe en gran medida a la Teoría del genio, que se comenzó a definir durante el siglo XVII y se consolidó en el siglo XIX, con el citado Romanticismo. En 1719, el abad Du Bos escribía en sus Reflexiones críticas sobre la poesía y la pintura una frase que describe perfectamente la especificidad del genio: "Lo que un hombre nacido con genio hace mejor es lo que nadie le ha mostrado cómo hacer". El genio, concebido como nativo, no necesita el aprendizaje de una tekhné ni el respeto por las reglas del arte de su propia época porque toma todo de sí mismo. La creación se presenta por lo tanto como un proceso misterioso -aunque indudablemente subjetivo- que ya no parece estar dominado por el esfuerzo de un trabajo fundamentalmente manual adquirido con la práctica y la experiencia. Esto no sólo se distancia de la antigua noción de artesano -que de allí en adelante da nombre a los productores de las denominadas artes menores o aplicadas y por lo tanto es una figura menos jerarquizada que la de artista- sino también de la valoración positiva del virtuosismo técnico, presente tanto en los pintores como en los escultores también durante el período de su definición como profesionales liberales. Lo que define la carencia del falsificador y le impide ser considerado un artista es justamente que no es un creador, ya que no produce una obra original y propia. De allí que un buen pintor cuyo estilo personal no haya tenido suceso puede seguir pintando y viviendo de su trabajo si acepta abandonar su estilo y su nombre propio y dedicarse a copiar el estilo de otro pintor que sí lo haya tenido. Es la concepción del artista creador -que se acota a una cierta y específica cultura aunque funciona como naturalizada- la que provoca que en ese movimiento el pintor se convierta en falsificador. La definición de artista creador sigue vigente como un lugar común, a pesar de los cuestionamientos provocados por las vanguardias desde principios del siglo XX -de los que me ocupo a continuación- y de las tempranas divergencias mostradas por un poeta $\mathrm{y}$ filósofo como Friedrich Schlegel a principios del siglo XIX -que retomaré luego-. Sin embargo son esos cuestionamientos los que parecen ubicar en una encrucijada a la falsificación. 


\section{El hacer cuestionado y la encrucijada de la falsificación}

Si bien todos los falsificadores nombrados hasta aquí han vivido en el siglo XX, muchas de sus falsificaciones se inclinan por obras de artistas muertos y con un lugar importante en el canon de pintura europea. ${ }^{9}$ Ello no se debe a un problema económico -las obras de artistas consagrados de siglos anteriores pueden alcanzar precios más elevados-, moral -de respeto por los artistas vivos- o incluso práctico o legal -el peligro de que el artista vivo reconozca la falsificación o impida falsar su atribución-, sino en gran parte a que el cuestionamiento a la noción de obra de arte y consecuentemente a la figura de artista que realizan algunas de las vanguardias, llega a poner en duda la utilidad de la falsificación.

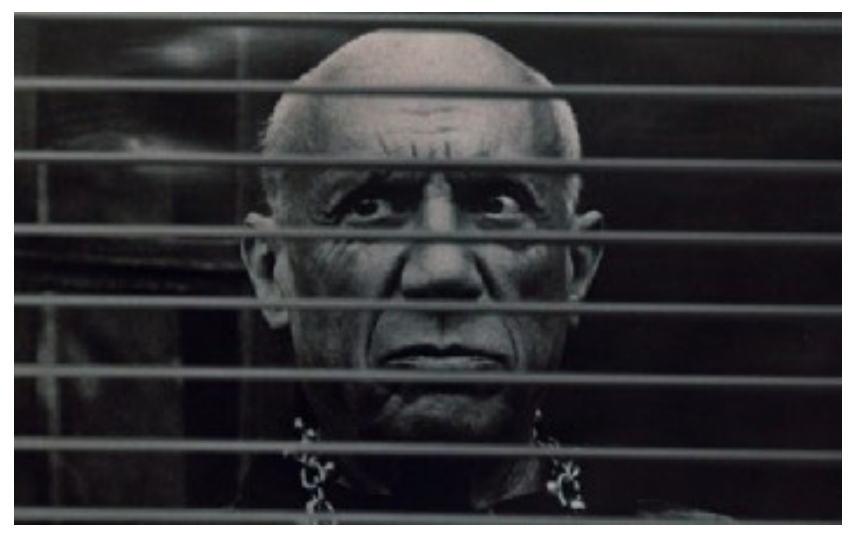

Sobre los impedimentos para la falsificación durante el siglo XX hay ejemplos con muy diverso estatuto, $\mathrm{y}$ algunos de ellos no están necesariamente probados: que Dalí firmara grabados, dibujos o pinturas pequeñas no realizados por él sino por ayudantes de su taller para vender más obra que la que podía realizar por sí solo, ${ }^{10}$ no hace más que mostrar la complejidad del problema, dado que en este caso lo único no falso es la firma, y su función es la de "legitimar" un fiasco voluntario. La firma como probatoria de autenticidad vuelve a aparecer, asemejándose a lo que ocurría en el Renacimiento, cuando todavía se mantenían los talleres de producción colectiva pero las obras ya se firmaban individualmente. En ese caso el maestro -a quien se encargaba la obra por su prestigio y reconocimiento- pintaba por ejemplo las figuras más importantes de la obra y los ayudantes completaban los fondos. Además de que no está probado, el supuesto ejemplo de Dalí es excepcional, de modo que no hace peligrar a la falsificación como práctica. $\mathrm{Si}$ se puede hablar de una encrucijada es en cambio por el cuestionamiento sobre la noción de obra -y su correspondiente efecto en la definición de artista- que realizan algunas de las denominadas vanguardias históricas. Si bien la ruptura con la concepción de obra como producto realizado manualmente y enmarcado en alguna de las denominadas artes visuales se produce con el dadaísmo y su apropiación de objetos fabricados en serie e industrialmente, así como por la apelación al azar, el humor y la paradoja como motores de la producción artística (en lugar del plan, el trabajo o incluso de la inspiración del artista genio), las vanguardias que no abandonan la pintura también producen cambios que afectarán a la falsificación. Algunos conceptos de Lévi Strauss sobre la pintura no figurativa pueden colaborar para analizar una producción que parece más resistente a la falsificación. En una cita al pie de El pensamiento salvaje, el antropólogo acota: "La pintura no figurativa adopta 'maneras' a guisa de 'temas', pretende dar una representación concreta de las condiciones formales de toda pintura. De esto resulta, paradójicamente, que la pintura no figurativa no crea, como lo cree, obras tan reales -sino más- como los objetos del mundo físico, sino imitaciones realistas de modelos inexistentes. Es una escuela de pintura académica, en la que cada artista se afana en representar la manera como ejecutaría sus cuadros si, por casualidad, los pintase." (1962, 20003:54) En la línea de este comentario se podría agregar que la pintura no figurativa no solamente realiza imitaciones realistas de modelos inexistentes, sino que se propone como un programa artístico estricto que reduce las posibilidades productivas al respeto por unas pocas reglas, ${ }^{11}$ de modo que las obras realizadas resultan variaciones de ese programa que conforman una serie que puede ser producida durante toda la carrera del artista. ${ }^{12} \mathrm{Si}$ se conocen sus reglas se puede intentar agotar sus posibles variaciones, lo que además de fortalecer la noción de serie de obras concebidas como conjunto puede ser equivalente, desde el punto de vista de su recepción y tomando el tono irónico de Lévi-Strauss, a que el conocimiento de una sola pintura-siempre y cuando se deduzcan las reglas del citado programa- permite el conocimiento de toda la serie. Si Genette define como pastiche el procedimiento de Van Meegeren que produce a la manera de Vermeer obras nuevas, el caso descrito se podría definir como autopastiche, pues la restricción ya no es de orden estilístico o genérico, sino que hay un programa conciente, producido voluntariamente por el artista y seguido hasta las últimas consecuencias. ¿Qué podría agregar entonces un falsificador de la modalidad Van Meegeren a esa serie?

Por supuesto, desde el punto de vista de la "historia de su producción" la pintura no figurativa fun- 
ciona igual que toda pintura, y comporta entonces el mismo grado de dificultad que la figurativa. Desde esa perspectiva falsificar un Pollock con sus chorreados y goteados -especialmente en la modalidad de réplica- es tan dificultoso como un Rembrandt, aunque por el adjetivo de cartelistas utilizado por Viñuela los artistas del siglo XX parezcan no ser altamente considerados por los dedicados falsificadores. Si la posesión de una tekhné es lo que permite convertirse en falsificador -aún con la exclusión de otros requisitos artísticos modernos como la facultad creadora- cuando tanto la tekhné como la creación se ponen en duda es inevitable que también se ponga en cuestión la utilidad de la falsificación. Cuando el Dadaísmo cuestiona el proceso de producción de la obra y con él la noción de obra de arte y el hacer del artista, afecta también el lugar de la falsificación, vinculado según la hipótesis que intento probar a esa figura de artista cuestionada. El nombre mismo que Duchamp da a sus producciones, ready made, da cuenta del cambio. El artista podrá de aquí en adelante no ser más el trabajador manual que con la posesión de una tekhné construye una obra singular, no existente antes como objeto. Como es sabido, la exhibición en un espacio de arte de un objeto de uso cotidiano y de producción en serie industrializada (un urinario de baño público, un portabotellas), con ninguna o escasa intervención por parte del artista, ${ }^{13}$ cuestiona por un lado tanto el aspecto artesanal como el de la creación, y por otro la definición de obra como objeto único. Ambos aspectos afectan el lugar de la falsificación: si no hay obra única ni original y si el artista ya no se define ni como poseedor de unatekhné ni como creador de objetos únicos y originales ${ }^{14}$ deja de tener sentido la atribución de esa obra a una firma que define su prestigio y su precio. ${ }^{15}$

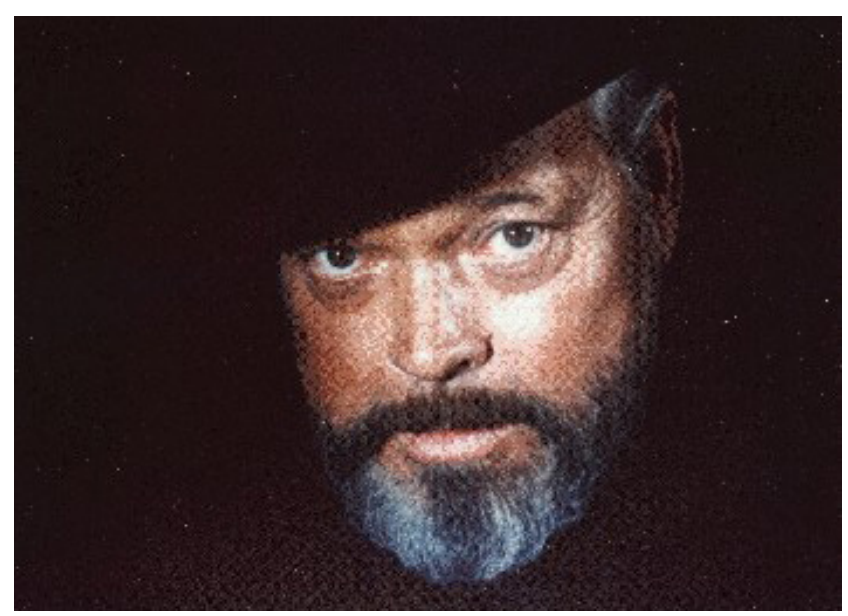

La muerte del artista: ¿una nueva encrucijada para el falsificador?

Todavía se escucha la crítica de: "Esto lo podría haber hecho yo" frente a una obra de vanguardia. Esa reacción, efecto de los cuestionamientos a la producción artística y a la figura de su hacedor antes descriptos, convive con un movimiento que tuvo su inicio en la década del sesenta del siglo XX pero cuyos antecedentes ya están presentes según Oscar Steimberg en alguna de las posiciones románticas refractarias a la concepción del artista creador. A principios del siglo XIX Friedrich Schlegel "presenta al artista como operador de la cultura que detona 'todos los lenguajes, conocimientos y ciencias'... y esos 'conocimientos, prácticas y operatorias son caminos de libertad para él (respecto de la costumbre, la repetición o las maneras de pensar los géneros en la comunicación)'” (Koldobsky 2003, con cita a Steimberg 1989 [1996]: 116-117). De modo que, contemporáneamente a la consolidación de la Teoría del genio y formando parte del primer Romanticismo -movimiento impulsor de la definición de artista creador-Schlegel describe al artista (poeta) como el que es capaz de beber de las ciencias, la religión, el arte y también de la tradición y la producción popular para producir una obra que es resultado de esos juegos y cruces, en lugar de serlo de una inspiración misteriosa y furtiva. Es de observar además que en ese gesto Schlegel propone romper con las rígidas jerarquías estéticas entre lo culto y lo popular o lo alto y lo bajo (aspecto programático compartido por el Romanticismo). En 1968 Roland Barthes escribe "La muerte del autor", texto en el que decreta la muerte del creador como sujeto pleno, en función de una posición que es un cruce de escrituras de las que el autor no es padre sino más bien hijo; es decir, no es productor sino producto; y en ese trabajo se observan ecos de las lejanas palabras de Schlegel. En artes visuales, al reconocimiento de las condiciones complejas e intertextuales que operan en el proceso de producción de una obra y que impiden hablar de un creador que toma todo únicamente de sí mismo, se suma el abandono de lo manual, que imprimía una huella física de la figura autoral en la obra y lo mantenía ligado a una materialidad (la obra era motivada física y existencialmente por la acción del pintor, escultor o grabador). La pérdida de la especificidad material de la pintura o la escultura en obras como las de Duchamp está acompañada de una expansión en los medios utilizados, de una acentuación del proceso sobre el producto y de un creciente privilegio de lo conceptual por sobre lo sensible o artesanal. La pregunta en la obra acerca de sus propias 
condiciones de posibilidad y la referencia al propio estatuto de lo artístico convocan más que a un artista creador, a un "productor crítico" (Koldobsky 2003), en la medida que no solamente recupera la propia historia del arte para reflexionar acerca del estatuto de la práctica artística y de sus condiciones de posibilidad ${ }^{16}$ sino que toma de otros lenguajes, tipos discursivos y prácticas culturales como la ciencia, el discurso político, el publicitario y el informativo para reflexionar sobre su funcionamiento. Esa figura disuelve su especificidad como "usurpadora" de otras especificidades, pero ello antes que afectar al falsificador afecta a su alter ego, el artista.

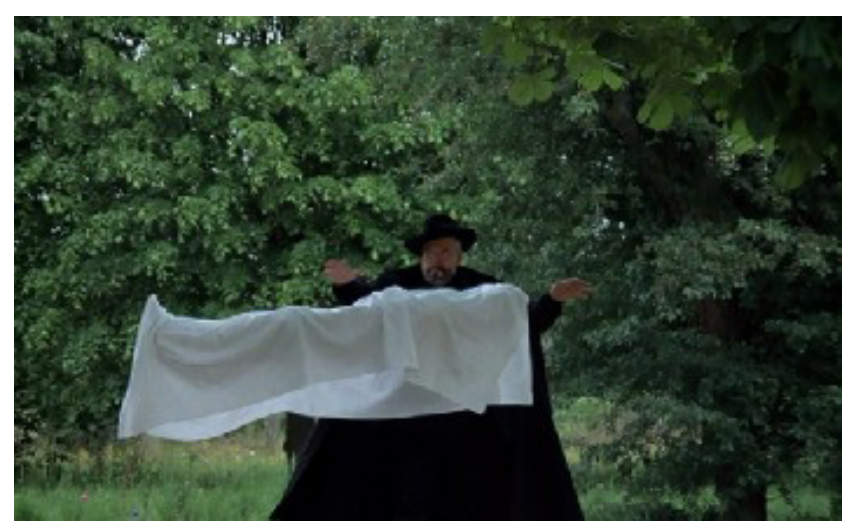

\section{Los encantos del falsificador y su paradoja}

Si bien gran parte de la producción de las artes visuales ha modificado sus soportes y materialidad -definiéndose en la actualidad como objetual, conceptual, performática, multimedial, tecnológica o incluso bioartística- todas esas manifestaciones conviven con la pintura. A pesar del reiterado anuncio de su muerte (contemporáneo al de la muerte del autor e incluso al del arte todo), se sigue produciendo pintura; $y$ a diferencia de la estricta normativa estilística que la condicionó durante siglos e incluso de la omnipresencia de registros como la representación mimética y la narración -que abarcaban en Occidente todo estilo regional, epocal o individual posible durante varios siglos- hoy conviven la pintura figurativa con la no figurativa, la mimética con la no mimética y la narrativa con la que no lo es. Así como la pintura ha sobrevivido lo ha hecho la falsificación, ya que los embates a la figura de artista creador único y original, cuya firma es prueba de la individualidad de su estilo y de la unicidad de la obra, no han llegado a destruir esa exitosa y naturalizada noción. Y la persistente presencia de la figura de artista creador, junto con el despliegue de un mercado del arte que parece complejizarse cada vez más, son las garantías de la continuidad de la existencia de la falsificación, cuya vida, en la medida que está atada a esa definición de artista y a esas condiciones históricas, no ha sido tan larga. Además de las condiciones que posibilitan su existencia, la falsificación -y especialmente la figura del falsificadorponen en escena una serie de tensiones entre conceptos caros a nuestra época. La producción de un objeto cuyo productor debe mantenerse en secreto, a costa de conocerse la infracción o incluso el quebrantamiento de la ley, no impide sin embargo que los falsificadores sean protagonistas de un célebre documental ( $F$ for fake) o sean entrevistados por diarios importantes con el objeto de "conocer sus secretos". El que no se haya probado la autoría real de muchas de las obras que se encuentran en museos permite que se sigan produciendo falsificaciones y que muchas adquieran, por la propia permanencia en las instituciones acreditadas del arte, el grado de autenticidad que su garantía aporta. Además de que no está probado que algunos de los más reconocidos falsificadores lo sean, muchos se presentan ante el mundo como restauradores, y alcanzan reconocimiento en esa actividad. Las tensiones entre legalidad e ilegalidad, clandestinidad o secreto y celebridad, tienen un encanto de los que la figura de artista carece, así como lo tiene sortear la opinión de reconocidos expertos en atribución de obras. Los saberes específicos que requiere la producción de una falsificación no sólo son pictóricos sino químicos y financieros entre otros. Trabajos como la búsqueda de la madera para producir el marco envejecido, la compra de una tela contemporánea pero de artista desconocido para que posea las huellas del tiempo, la experimentación de los elementos y técnicas propias de una época, y la concienzuda práctica frente a obras originales para lograr la textura del trazo y la rugosidad propia de la superficie, se suman a la copia de los rasgos de estilo personal del artista. Se necesitan finalmente trabajosos procedimientos de envejecimiento del producto final, y una vez terminada la obra, conocer los circuitos de su inclusión en el mercado legal. Todo ese proceso prueba las tensiones fundamentales en las que se sostienen sus encantos dominantes. La figura del falsificador es la de un trabajador en una era de arte sin trabajo, o por lo menos sin privilegio del trabajo; y expone -en contra de su propio deseo- un desprendimiento del orgullo y la vanidad presentes en la exposición pública de los talentos personales, en un tiempo en el que todavía el sujeto creador en tanto figura individual sigue cubierto de gloria hasta el punto de que se le promete el acceso a posteridad. De ese modo, el falsificador cuestiona la figura de artista individual tanto como su estatus social o económico. Con su anacronía política y en una posición 
mucho más marginal que la de la vanguardia, cuestiona la propiedad privada del talento. Sujeto fantasma, sólo puede ser admirado a costa de que salga a la luz como infractor e incluso delincuente, aunque más no sea sin ser probado. $F$ for fake tematiza la falsificación y a los falsificadores, pero no sólo porque habla de ellos ni porque lo proclama sino porque lo hace su organización discursiva. En ese movimiento, es la propia operatoria del documental de Welles la que cuestiona la figura del autor, y del mismo modo, son las obras de los falsificadores junto con su ambigua invisibilidad, las que paradojalmente ponen en cuestión a la figura sin la cual no existirían, la del artista.

\section{Referencias}

Benjamin, W. $(1931,2004)$ "La obra de arte en la era de su reproductibilidad técnica”, en Sobre la fotografía. Valencia, Pre-textos.

Dubois, P. (2002) "Máquinas de imagen: una cuestión de línea general”, en Video, Cine, Godard, Buenos Aires: Libros del Rojas (UBA).

Genette, G. (1997) La obra del arte, Barcelona, Lumen.

Ginzburg, C. "Indicios”, en Mitos, emblemas, indicios, Barcelona: Gedisa.

Heinich, N. (1996) Étre artiste, París: Klincksieck.

Koldobsky, D. (2003) “Escenas de una lucha estilística. La memoria del arte argentino en la prensa gráfica de los sesenta”, Figuraciones $n^{\circ} 1 / 2$ - Ärea transdepartamental de Crítica de Artes (IUNA), Buenos Aires: Asunto impreso. - (2003) "La figura de artista cuando se decreta su muerte", Informe final de la beca de Formación Superior en la investigación, UNLP

Schaeffer, J. M. y Flahault, F. (1996) La création. Revista Communications. París, Seuil.

Steimberg, O. (1989) “En la línea de los discursos interrumpidos", en Steimberg, O. y Traversa, O: Estilo de época y comunicación mediática. Buenos Aires: Atuel, 1996.

1 Si bien entonces en literatura o música se podrá hablar por ejemplo de ediciones "piratas", se trata en esos casos de comercialmente fraudulentas, pero no de "no auténticas" ya que, a diferencia de la inmanencia física que define objetualmente y por su historia de producción por ejemplo a la pintura, en estos casos Genette habla de inmanencia ideal. Sin embargo hay un aspecto autográfico en ellas, que es el que mantiene su carácter objetual: es posible falsificar el manuscrito de un libro (1997: 22-24).

2 Si bien no es objeto del presente trabajo, es de interés notar otra diferencia respecto de la comprobación de una falsificación en pintura y de un plagio literario: si en pintura la figura del experto es fundamental para reconocer las posibles diferencias respecto del estilo del artista falsificado, en literatura ha ocurrido más de una vez -y en el panorama argentino recientemente- que son los lectores los que reconocen la semejanza de la obra que están leyendo con otra, muchas veces cuando esa obra ha ganado un concurso definido justamente por expertos que no han notado sus semejanzas con otra obra anterior.

3 Elmyr d'Hory es un célebre falsificador húngaro fallecido en 1976, cuyas obras han alcanzado altos precios incluso una vez conocida su autoría real. Parte del objeto del presente trabajo es comprender los mecanismos del encanto de esta impostura, encanto que tiene en cuenta $F$ for fake al dar un lugar preeminente a la figura de d'Hory y a su biógrafo. La operación con la que se genera el documental de Welles, por otra parte, es la de tomar material ya filmado sobre este falsificador y producir su obra a partir de allí, en una suerte de bricolage que se reconoce como efecto final y que a su vez desvía el interés protagónico de la persona de d'Hory hacia la reflexión acerca de qué es falsificar.

$4 \quad$ En su formulación de lo que define como un paradigma de inferencias indiciales, Carlo Ginzburg recupera a una figura muy citada por los historiadores del arte del siglo XX, la de Giovanni Morelli, un estudioso que en el último tercio del siglo XIX propuso un método para reconocer la autenticidad de la autoría de una pintura, basado en el reconocimiento de los "detalles menos trascendentes y menos influidos por las características de la escuela pictórica a la que el pintor pertenecía: los lóbulos de las orejas, las uñas, la forma de los dedos de manos y pies". Este método, que fue conocido como método morelliano, no solamente requiere saberes sobre estilos e historia del arte en general, sino también una gran experiencia de conocedor, que Ginzburg plantea como fundadora del moderno concepto científico de las ciencias humanas. (1994: 139). Además el autor reconoce en esos detalles la figura del síntoma psicoanalítico, pero si es por ellos que según Morelli se puede descubrir el fraude, en $F$ for fake Welles demuestra que son los pequeños detalles verdaderos los que permiten construir el verosímil sobre el que una obra se sostiene, porque en el caso de su documental son los pequeños datos verdaderos los que permiten construir la relación con el referente y los que tiñen a los que no lo son con efecto de veracidad.

5 Se observará en las palabras de Antonio Viñuela, citadas más adelante, que según su opinión el único problema de los falsificadores es que, a pesar de ser genios, son poco conocidos. Sin embargo, él mismo logró convertirse en personaje reconocido como el mejor falsificador de pintura clásica española, ya que si bien la policía española considera que parte de los Velázquez y Murillo que pertenecen a respetables colecciones son obra suya, no lo han podido probar (Diario El mundo, 24/4/94). De modo que, como ya se pudo vislumbrar en la nota anterior con el caso de d'Hory, falsificación y celebridad no están reñidos del todo. Sobre esto volveremos más adelante. 
6 Utilizo entrecomilladas las palabras "fabricación" y "hacedor" para diferenciarlas de producción y artista, que pueden remitir directamente a la figura que el falsificador suplanta o imita.

$7 \quad$ Según Dubois, la tekhné es un "arte del hacer humano" que se puede definir como "Procedimiento de fabricación que responde a reglas determinadas y conduce a la producción de objetos, bellos o utilitarios, materiales o intelectuales” (2002)

"En la Edad Media las “artes mecánicas” distinguen a las actividades manuales -que, sujetas por la práctica no dependen del discurso escrito- de las denominadas "artes liberales", compuestas por el trivium (gramática, retórica y dialéctica) y el quatrivium (aritmética, geometría, astronomía y música), asignaturas que se enseñan en las nacientes universidades” Koldobsky 2003, "La figura de artista cuando se anuncia su muerte".

$9 \quad$ El protagonista del film de Welles, Elmyr d'Hory, falsificaba en cambio obras de Picasso, Matisse y Modigliani, artistas de vanguardia y del siglo XX, pero especialmente en el caso de los dos primeros, su gran cantidad de producción, extendida por largas carreras debidas a largas vidas, y sus cambios estilísticos -que de todos modos no abandonaban la coherencia ni las marcas de autorpueden justificar que d'Hory trabajara sobre pinturas de artistas contemporáneos a él. La hiperbólica figura y producción de Picasso -que pintaba varias obras a la vez y muchas de ellas eran terminadas en el día- además de convertirse en un paradigma del artista moderno (y como tal presente en uno de los falsos episodios de $F$ for fake), permite argumentar la posibilidad de que él mismo pudiera dudar acerca de la autoría de algunas de ellas.

$10 \quad$ Las palabras de otros, como el pintor catalán Manuel Pujol Baladas, funcionan como toda prueba existente. El afirma que: "Yo le vi (a Dalí) firmar miles de hojas en blanco, que después pintaban artistas de ocasión” (Diario El mundo, 24/4/94)

11 La producción artística restrictiva tiene en el campo de la literatura un proyecto exitoso nacido en 1960: el grupo francés Oulipo, acrónimo de "Ouvroir de littérature potentielle", que crea obras a partir de "contraintes", es decir a partir de restricciones. Con el objetivo de producir una literatura lúdica y experimental, son ejemplos de ella el famoso La disparition, novela de Georges Perec que no contiene ninguna palabra con la letra e.

12 Casos como los de Mondrian o Rothko -tan diferentes entre sí como Miró respecto de Tápies y a su vez en relación con ellosson ilustrativos de un programa reductivo seguido durante gran parte de una carrera. Los célebres rectángulos de colores primarios del neoplasticismo puro de Mondrian son equivalentes a las denominadas "banderas" de Rothko, con sus bandas de contornos indefinidos y tamaños variables que combinan dos o tres colores por cuadro por toda operatoria. En ese lugar se podría ubicar también al más famoso de los pintores argentinos contemporáneos, Guillermo Kuitca, quien a pesar de no hacer estrictamente pintura no figurativa ni dedicarse durante toda su carrera a un único "programa reductivo" ha desarrollado su obra en relación con series de pinturas/objetos a partir de distintos programas o modelos: los mapas, los teatros, los planos de cementerios, etc.

13 El mismo Genette diferencia entre los "ready made asistidos", por ejemplo el célebre urinario, al que además de ser titulado Fountain -con un gesto ingenioso o irónico- Duchamp modificó levemente y firmó con un seudónimo antes de ser exhibido, y el Portabotellas, que además de no ser modificado físicamente no estaba firmado ni tenía otro título que la denotación del nombre del objeto (1997:155,156), para mostrar los distintos grados de distanciamiento respecto de la noción de obra de arte antes vigente.

14 Si bien Benjamin describe el cuestionamiento del aura en relación con la reproductibilidad técnica de las imágenes a partir de la existencia de la fotografía, se puede inferir el mismo cuestionamiento cuando la obra en su concepción niega la unicidad (o, como veremos, parece hacerlo) porque se trata de un objeto construido en serie y sobre el que las manos del artista no pueden haber dejado las huellas de su trabajo productivo. Por otra parte, incluso se puede pensar en un aura desplazada desde la obra a la figura del artista, como parecen indicarlo las palabras del mismo Duchamp: "Yo creo en el artista; el arte es un espejismo". En ellas se observa que más que redefinir irónicamente la noción de artista, su acción está vinculada a hacerlo simplemente con la de arte. Sin embargo no hay posibilidad de que una no afecte a la otra.

15 Sin embargo, este cuestionamiento no es del todo efectivo: el hecho de que en la actualidad los ready made de Duchamp sean exhibidos como "originales" (los que pasaron por las manos del artista, aunque no hay un sólo ejemplar de cada uno) habla de la fuerza que tiene el objeto como fetiche y de la dificultad de desprenderse del valor cultual dado por la unicidad. Pero ese problema no puede ser desarrollado aquí, y además no afecta al cuestionamiento que esa forma de arte realiza a las nociones de obra única y de artista creador.

16 Operación explícitamente representada por Duchamp en su apropiación de la Gioconda con bigotes en clave de burla, y más adelante por todo un movimiento desarrollado en Estados Unidos justamente bajo el nombre de apropiacionismo, con el mismo grado de explicitación pero en el que las mismas obras de Duchamp son retomadas y homenajeadas. En todo caso lo que se modifica es el posicionamiento de esa mirada: la ironía está permitida cuando se trata de un gesto primero, pero muchas décadas después de las vanguardias históricas aparece el escepticismo o el simple reconocimiento del modo de funcionamiento de esas operatorias. 